\title{
Hardening Characteristics of Plain Carbon Steel and Ductile Cast Iron Using Neem Oil as Quenchant
}

\author{
${ }^{1}$ Hassan, S. B, ${ }^{2}$ Agboola. J.B, ${ }^{1}$ Aigbodion, V.S. and ${ }^{1}$ Williams, E.J. \\ ${ }^{1}$ Department of Metallurgical and Materials Engineering, Ahmadu Bello University, Samaru, \\ Zaria, Nigeria. \\ ${ }^{2}$ Department of Mechanical Engineering, Federal University of Technology, Minna, Nigeria. \\ E-mail, hassbolaji@yahoo.com, joe_agboola@yahoo.com, aigbodionv@yahoo.com
}

\begin{abstract}
The hardening characteristics of medium carbon steel and ductile cast iron using neem oil as quenching medium has been investigated. The samples were quenched to room temperature in Neem oil. To compare the effectiveness of the neem oil samples were also quenched in water and SAE engine oil the commercial quenchants. The microstructures and mechanical properties of the quenched samples were used to determine the quench severity of the neem oil. The result shows that hardness value of the medium carbon steel increased from $18.30 H V N$ in the as-cast condition to 21.60, 20.30and 20.70HVN while that of ductile cast iron samples increased from 18.90HVN in the as-cast condition to 22.65, 20.30 and $21.30 H V N$ for water, neem oil and SAE40 engine oil respectively. The as-received steel sample gave the highest impact strength value and water quenched sample gave the least impact strength. The impact strength of the medium carbon steel samples is 50.84, 41.35, 30.50 and 45.15 Joule and that of ductile iron is 2.71, 1.02, 0.68 and 1.70 Joule for as-cast condition, neem oil, water and SAE 40 engine oil quenched respectively. The microstructure of the samples quenched in the Neem oil revealed the formation of martensite. Hence, neem oil can be used where cooling severity less than that of water but greater than SAE 40 engine oil is required for hardening of plain carbon steels and ductile cast iron.
\end{abstract}

Keywords: Hardening characteristics, Ductile Cast iron, Medium Carbon Steel, Neem oil and Quenchant. 


\section{INTRODUCTION}

Plain-carbon steels and cast irons are heated to austenitising temperatures and then rapidly cooled (quenched) in water, brine, or oil to the critical temperature [1-2]. The critical temperature is dependent on the carbon content, but as a general rule is lower as the carbon content increases [1-3]. This results in a martensitic structure; a form of steel or cast iron that possesses a super-saturated carbon content in a deformed body-centered cubic (bcc) crystalline structure, properly termed body-centered tetragonal (bct). This crystalline structure has a very high amount of internal stress [4]. Due to internal stress quenched steel and ductile cast iron is extremely hard but brittle, usually too brittle for practical purposes [4-5]. These internal stresses cause stress cracks on the surface [5].

The commonly used quenchants are water, oil, brine, and synthetic solutions. Water though abundant and low cost has the drawback of inducing crack or dimensional changes on the quenched component due to its high cooling rate and oil has the problem of not inducing enough hardness. Polymer quenchant though can provide severity between those of water and oil has the problem of varying concentration during the quenching process and it is also more expensive. Brine produces more quenching severity than water; but it also has a problem of corrosive attack on the components and the equipment used for the quenching [1,5-7]. There therefore a need for the development of a quenching medium with good economics like water having less severity of quench and yet producing appreciable hardening. Hence this work is aimed at investigating the suitability of using neem oil as a quenching medium for hardening process in medium steel and ductile cast iron.

Neem, botanically known as Azadirachta Indica, is a soft natural insecticide, safe, eco-friendly and bio-degradable. Neem is known for its bitter taste due to a group of organic compounds called tetranortriterpenoids or more specifically, limonoids [8].

Nigeria is blessed with abundance of neem trees especially in northern parts of the country where it is used as shelter - belts for afforestation. Almost every part of the tree is useful especially in cosmetics, medicine and agriculture. The seeds and leaves for example, contain compounds with demonstrated antiseptic, antiviral and antifungal activity. The seeds which are neglected and of environmental nuisance/wastes are indeed "green gold”, where the oil is extract [8].

\section{EXPERIMENTAL PROCEDURE}

\subsection{Materials}

Materials used in this study are; medium carbon steel, Ductile Cast iron, Neem oil, water and SAE 40 engine oil as quenching media. The chemical composition of the steel and cast iron is shown in Table 1 and Table 2 shows properties of Neem oil. 


\subsection{Equipment}

The equipment used in this research includes: Lathe machine, Heat-treatment Furnace, Hand grinding deck of abrasive papers and rotary wheel for polishing; Metallurgical Microscope, Izod impact test; Digital hardness machine.

Table 1: Composition of the Medium carbon steel and Ductile cast Iron[9]

\begin{tabular}{|l|c|c|c|c|c|c|c|c|c|}
\hline & $\% \mathrm{C}$ & $\% \mathrm{Si}$ & $\% \mathrm{Mn}$ & $\% \mathrm{P}$ & $\% \mathrm{~S}$ & $\% \mathrm{Cr}$ & $\% \mathrm{Ni}$ & $\% \mathrm{Mg}$ & $\% \mathrm{Mo}$ \\
\hline $\begin{array}{l}\text { Medium } \\
\text { carbon steel }\end{array}$ & 0.442 & 0.305 & 0.91 & 0.026 & 0.021 & 0.049 & 0.042 & 0.0094 & 0.010 \\
\hline Ductile iron & 3.81 & 2.70 & 0.26 & 0.06 & 0.042 & 0.032 & 1.85 & 0.04 & 0.009 \\
\hline
\end{tabular}

Table 2: Properties of Neem oil

\begin{tabular}{|c|c|c|c|c|c|c|c|c|}
\hline Colour & $\begin{array}{c}\text { Boiling } \\
\text { Point }\end{array}$ & $\begin{array}{c}\text { Freezing } \\
\text { point }\end{array}$ & $\begin{array}{c}\text { Flash } \\
\text { point }\end{array}$ & PH & $\begin{array}{c}\text { Specific } \\
\text { gravity }\end{array}$ & $\begin{array}{c}\text { Free fatty } \\
\text { valve }\end{array}$ & $\begin{array}{c}\text { Saponification } \\
\text { value }\end{array}$ & $\begin{array}{c}\text { Iodine } \\
\text { value }\end{array}$ \\
\hline $\begin{array}{c}\text { Dark } \\
\text { Green } \\
\text { Brownish }\end{array}$ & $175^{\circ} \mathrm{C}$ & $14^{\circ} \mathrm{C}$ & $>175^{\circ} \mathrm{C}$ & $6.5-7.5$ & 0.915 & $42.3 \%$ & $180 \mathrm{mg}$ & 74.9 \\
\hline
\end{tabular}

\subsection{Method}

\subsubsection{Hardening process}

Cylindrical impact test sample of $11.47 \mathrm{~mm}$ in diameter and $71 \mathrm{~mm}$ length was machined from the samples. The samples were initially normalized, followed by austenitizing at $860^{\circ} \mathrm{C}$ for 15 minutes and then quenched in neem oil, water and SAE 40 engine oil respectively. Mechanical property tests were carried out on the as-quenched samples to determine the severity of the Neem oil as quenchant and compared with water and SAE 40 engine oil. Metallographic analysis was carried out for each as-quenched sample in the selected media.

\subsubsection{Hardness value determination}

The hardness values of the samples were determined using a digital Vickers Hardness (HVN) testing machine due to its high accuracy [9]. The samples were mounted in bakelite for better handling and proper flatness. The surfaces were thoroughly polished before samples were tested. The various hardness values were recorded in HVN. 


\subsubsection{Impact strength determination}

The notched impact samples quenched in the selected media were subjected to impact test from the weighted pendulum load on the Izod type impact testing machine. Sample of $11.47 \times 71 \mathrm{~mm}$ with a $2 \mathrm{~mm}$ deep notch of angle of $45^{\circ}$ was used [11].

\subsection{Metallographic Examination}

The as-quenched specimens in the various selected quenching media were mounted on Bakelite powder before grinding. Grinding of the samples was carried out manually on a water lubricated grinding machine using silicon carbide abrasive paper of grades 180, 240, 400 and 600 grit sizes. The ground samples were then polished to completely remove the fine scratches and make the surface smoother. Polishing was carried out on a rotating disc covered with polishing cloth impregnated with $1 \mu$ alumina solution. The disc rotated at a speed of 100-400rpm. The sample is rotated slightly against the surface of the impregnated polishing disc so that it skids over the paste without touching the fibers of the polishing cloth. The final polishing was carried out with 0.5 micron alumina polishing solution until the surface of the samples became scratch free and mirror like. The specimens were then etched with $0.5 \% \mathrm{HF}$ solution. After etching, the samples were washed in running water and alcohol and then dried in hot air. The etched samples were then placed on the sample stage of a metallurgical microscope and the microstructures obtained were recorded with the aid of the in built camera [9-11].

\section{RESULTS AND DISCUSSION}

The microstructures of the as-cast and as-quenched samples are presented in Micrographs 1-8.

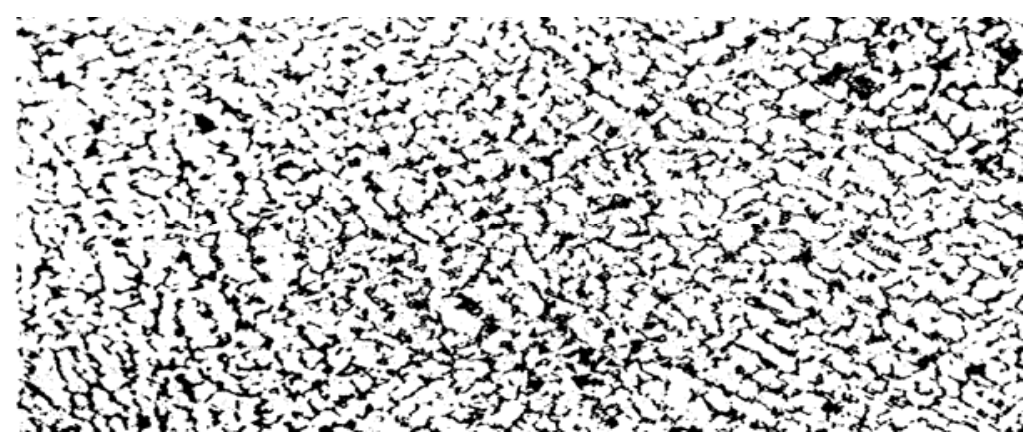

Micrograph 1: $\quad$ Microstructure of as-received medium carbon steel. The structure consists of ferrite (white) and pearlite (dark (x200). 


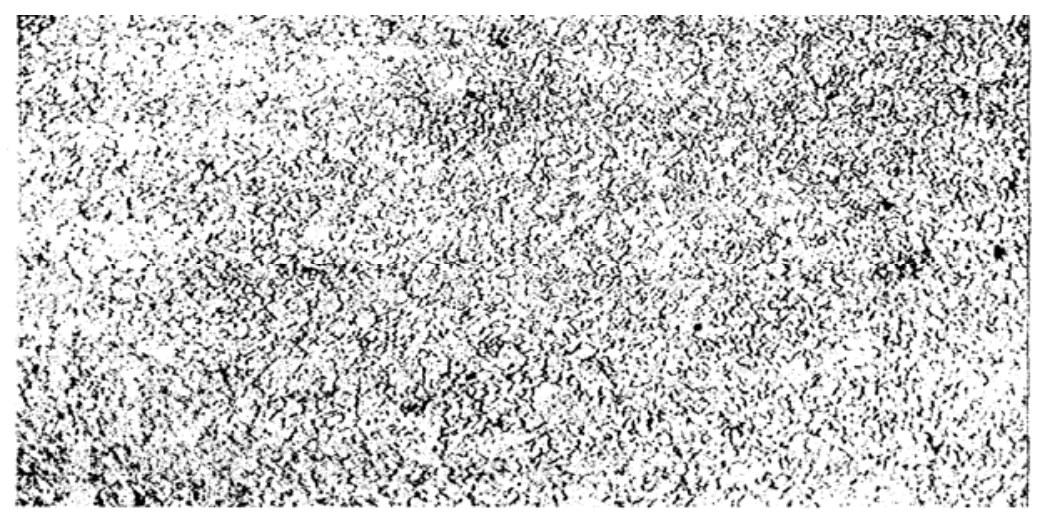

Micrograph 2: Microstructure of water quenched medium carbon steel sample. The structure consists of massive martensite (x200).

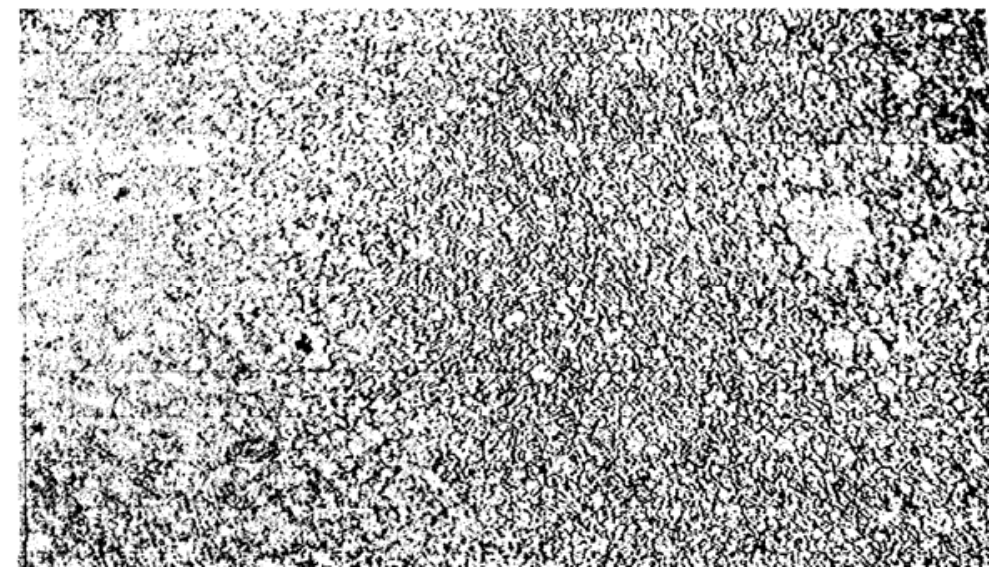

Micrograph 3: Microstructure of engine oil quenched medium carbon steel sample. The structure consists of mainly martensite. (white)( x200). 


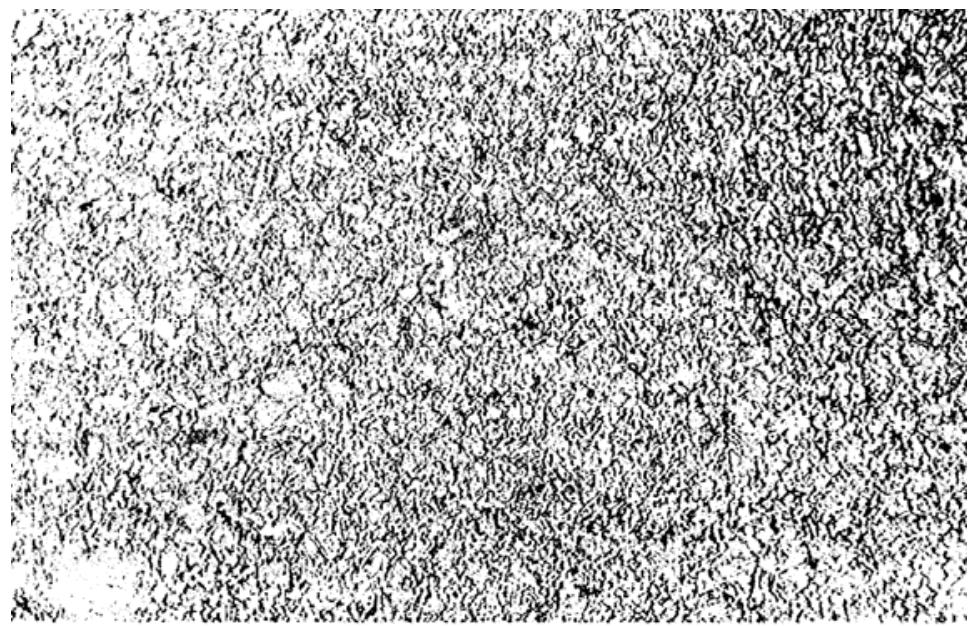

Micrograph 4: Microstructure of Neem oil quenched medium carbon steel sample. The structure consists of mainly martensite (white) (x200).

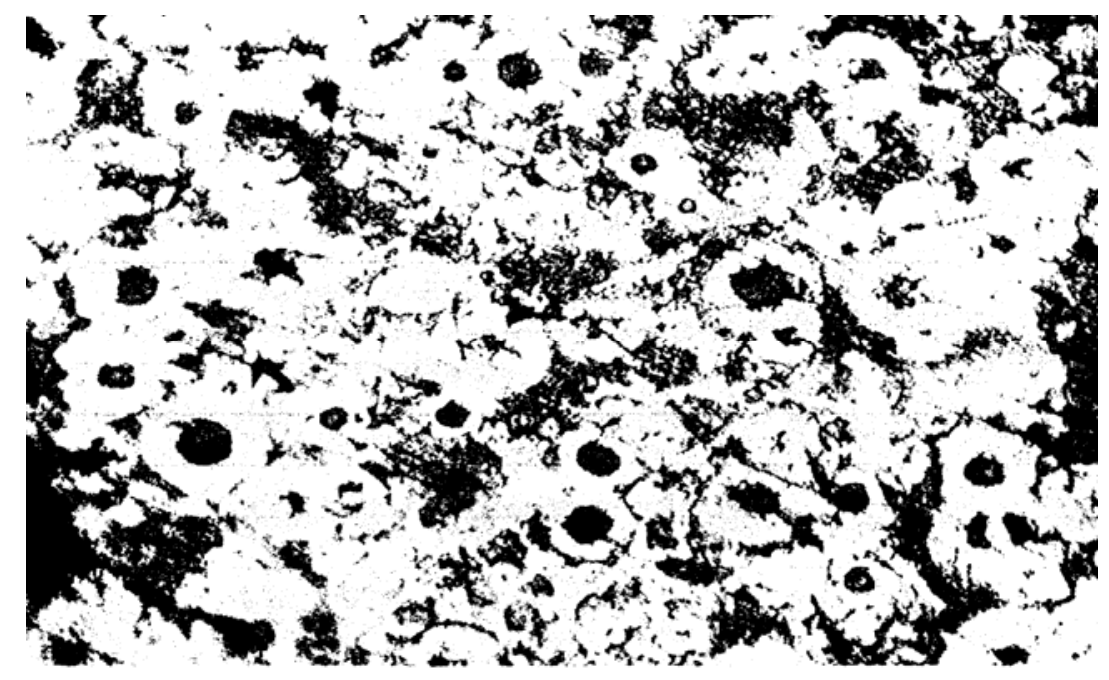

Micrograph 5: Microstructure of as-received nodular cast iron sample. The structure consists of graphite nodules surrounded by ferrite ring (white) in a pearlite matrix (dark) with some bull-eye structure (x200) 


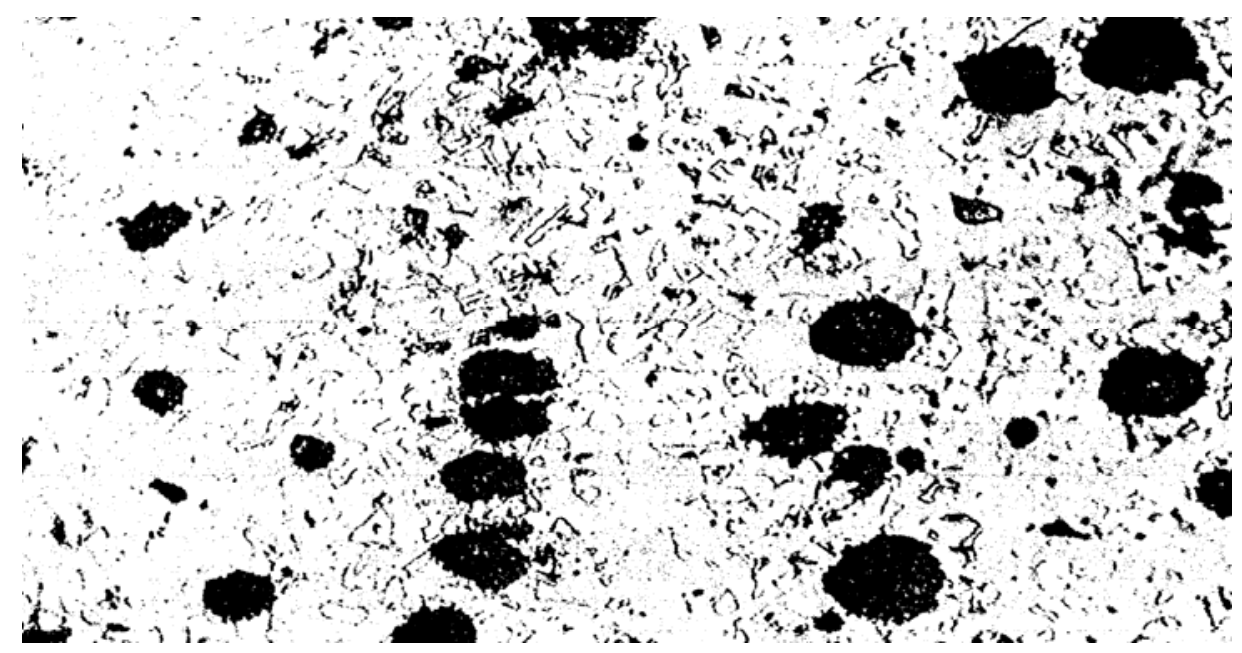

Micrograph 6: Microstructure of water quenched nodular cast iron sample. The structure consists of graphite nodules (black ball) in martensite matrix (white)(X200).

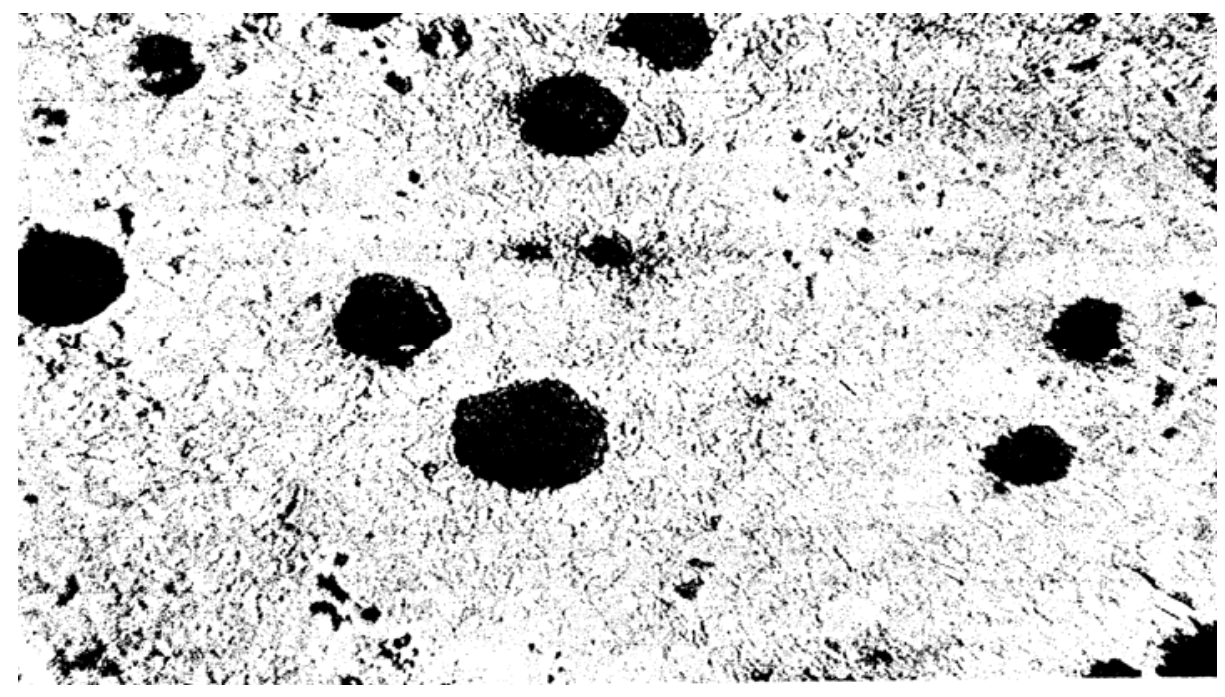

Micrograph 7: Microstructure of SAE 40 engine oil quenched nodular cast iron sample. The structure consists of graphite nodules (Black ball) in martensitic matrix (white)(x200). 


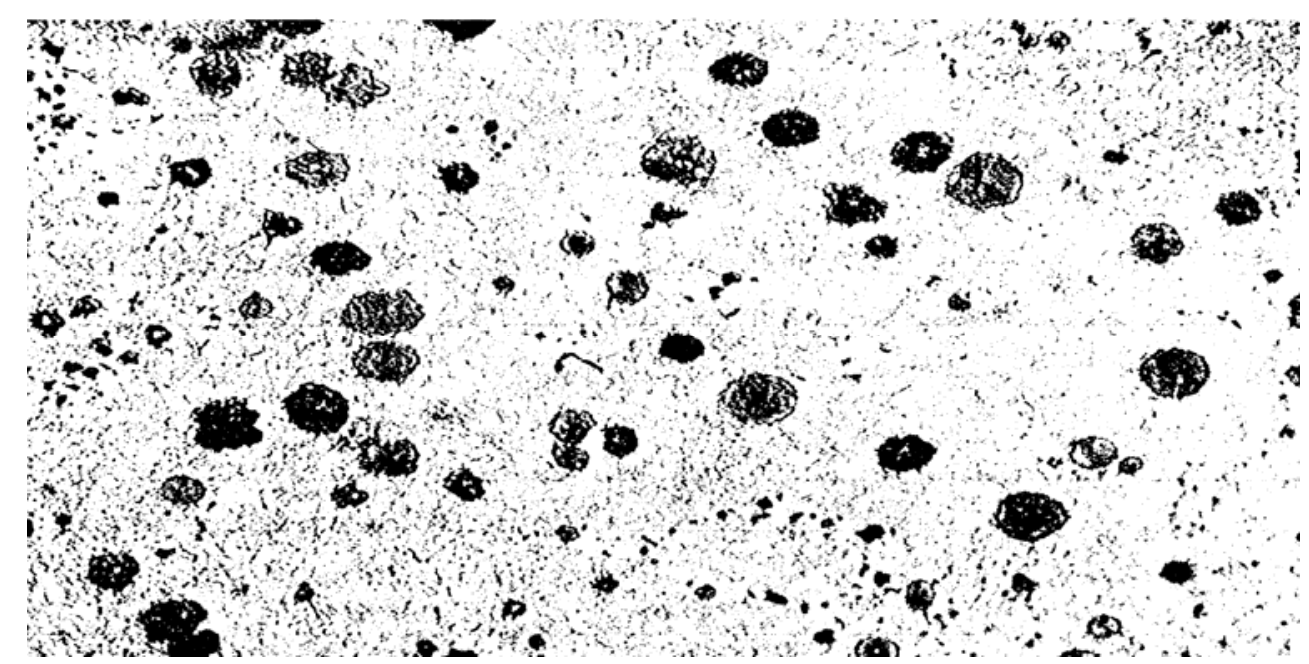

Micrograph 8: Microstructure of neem oil quenched nodular cast iron sample. The structure consists of graphite nodules (black ball) in martensitic matrix (white)(x200)

The microstructure of the as-cast medium carbon steel revealed the presence of pearlite and ferrite structure (see Micrograph 1). The microstructure of the quenched samples in water show the structure consisting of high proportion of martensite with retain austenite (see Micrograph 2). Microstructure of steel sample quenched in SAE engine oil revealed martensite structure and banitic structure (see Micrograph 3). The microstructure of sample quenched in neem oil reveal the formation of martensite with less retained austenite (see Micrographs 4). All microstructures developed are in line with the earlier observation of [6-7, 9-11].

The microstructure of the as-cast ductile cast iron consists of graphite nodules surrounded by ferrite ring in a pearlite matrix (see Micrograph 5). While the microstructure of water quenched ductile cast iron consists of graphite nodules in martensite matrix with retained austenite (see Micrograph 6), microstructure of SAE 40 engine oil quenched nodular cast iron sample consists of graphite nodules in martensitic matrix (see Micrograph 7). Microstructure of neem oil quenched nodular cast iron sample consists of uniform distribution of graphite nodules in martensitic matrix(see Micrograph 8). All microstructures developed are in par with the earlier observation of $[5,10]$.

The results of the mechanical properties of as - quenched samples in the various selected media are shown in Figures 1-4. 


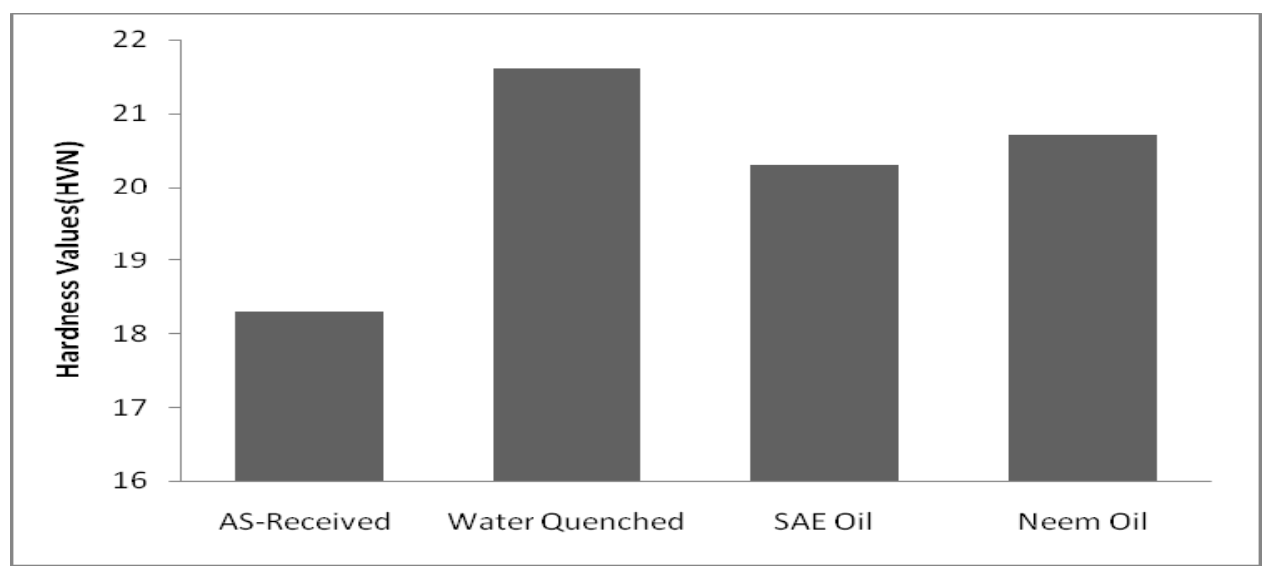

Figure 1: Variation of Hardness values with Quenching Media for Medium Carbon Steel

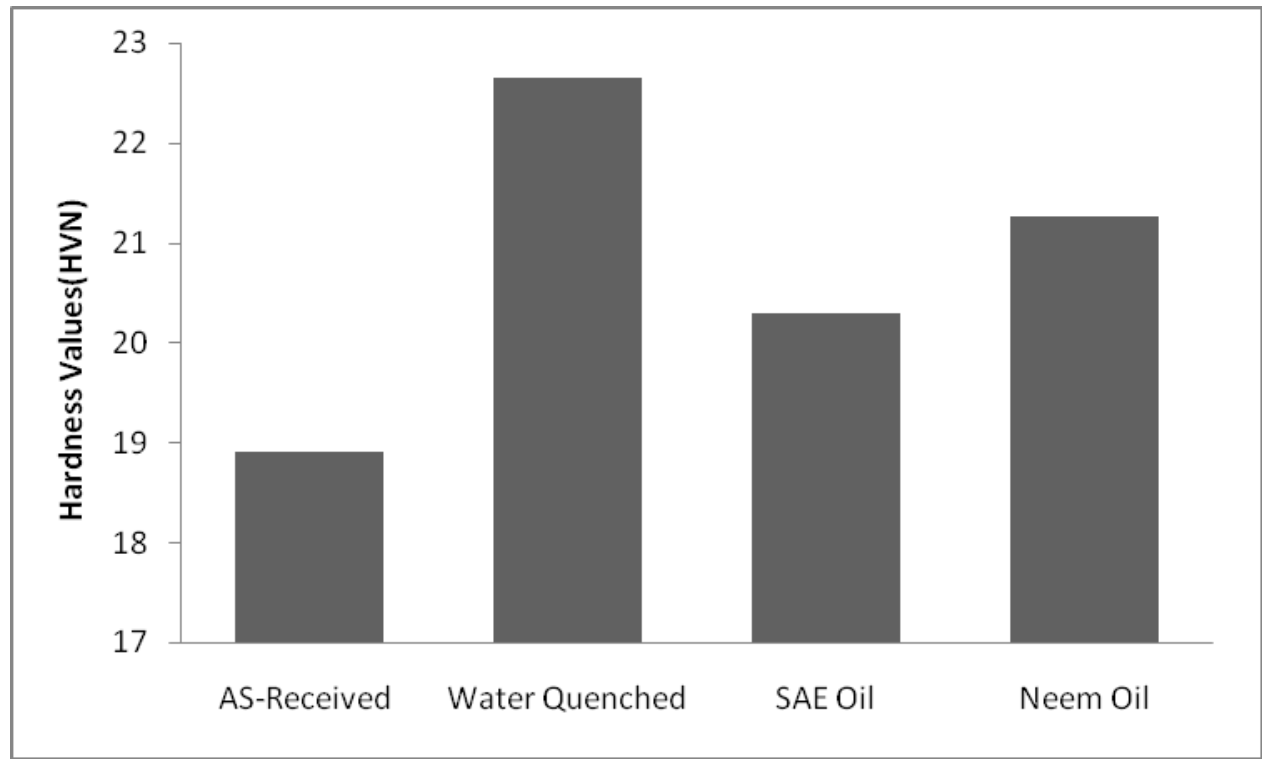

Figure 2: Variation of Hardness values with Quenching Media for Ductile Cast Iron 


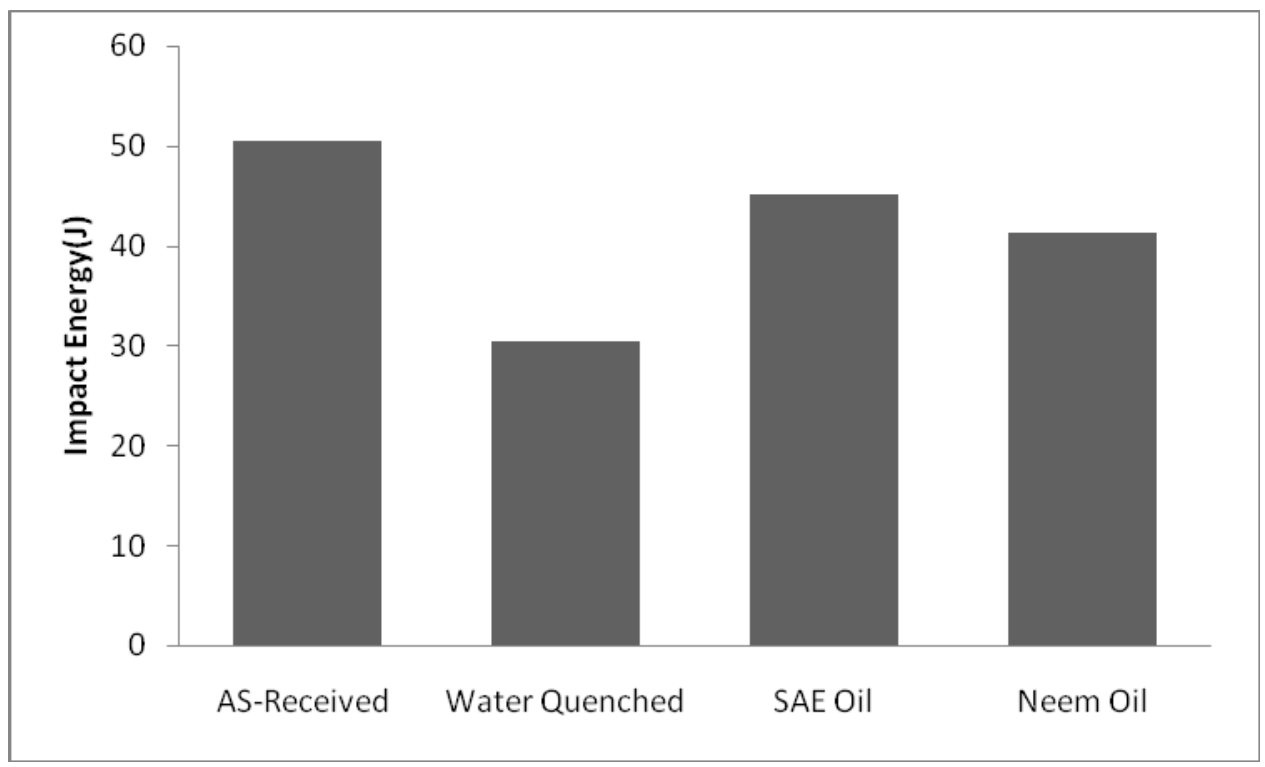

Figure 3: Variation of Impact Energy with Quenching Media for Medium Carbon Steel

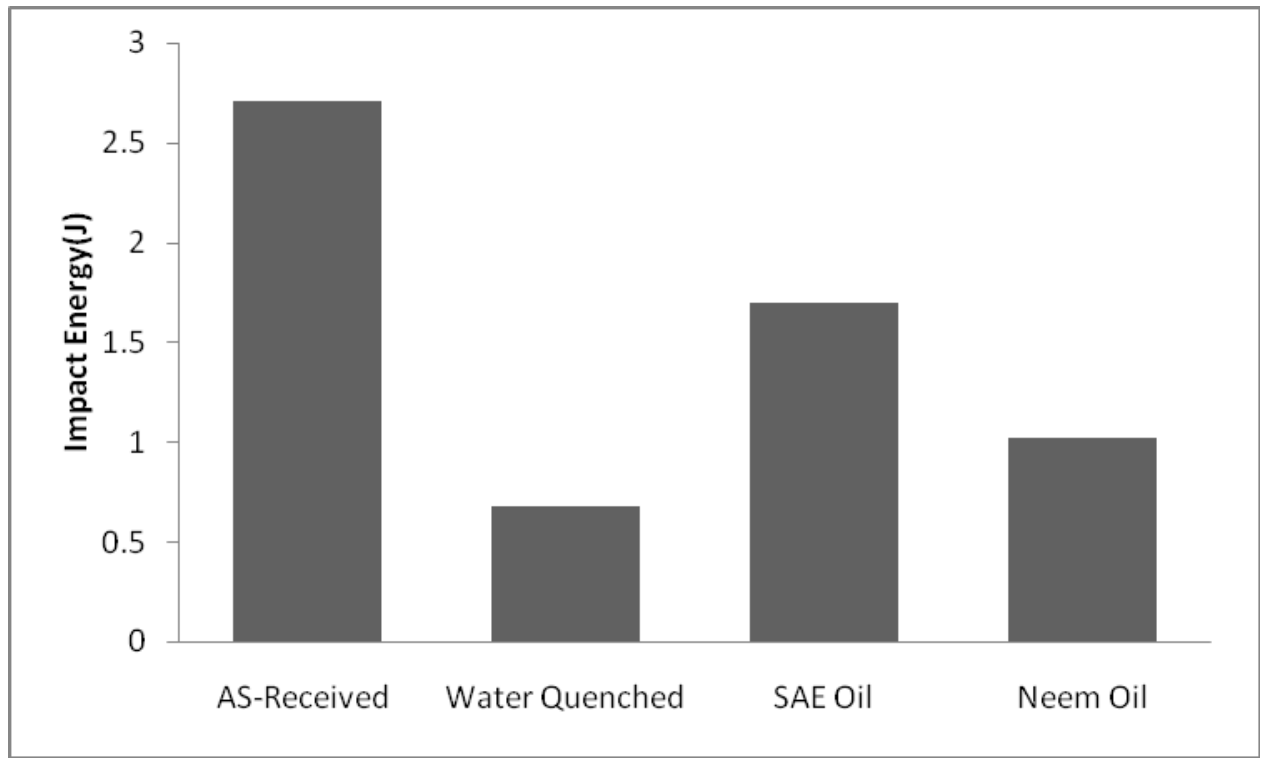

Figure 4: Variation Impact Energy with Quenching Media for Ductile Cast Iron

From the results obtained, the hardness value of both the medium carbon steel and ductile cast iron samples increased after quenching in all the media (see Figures 1 and 2). The quenched samples in the neem oil have a lower hardness values as compared to water. This may be attributed to the fact that water have a higher cooling rate than neem oil [6-7]. 
The hardness values of the as-cast condition, neem oil, water and SAE 40 engine oil quenched are 18.30, 20.70, 21.60 and 20.30HVN for medium carbon steel and 18.90, 21.27, 22.65 and 20.30 for ductile cast iron respectively (see Figures 1 and 2). Water quenched produced the highest hardness value and SAE 40 engine oil produced the least after quenching. The high hardness values and impact strength obtained in these results can be attributed to the various microstructures obtained (see Micrographs 1-8). Neem oil developed hardness between that of water and SAE 40 engine oil.

The hardening process by quenching in all the liquid media reduced the impact energy (see Figures 3 and 4). The as-received samples gave the highest impact strength value and water gave the least impact strength. The impact strength of the medium carbon steel samples is 50.84, $41.35,30.50$ and 45.15 Joule and that of ductile iron is $2.71,1.02,0.68$ and 1.70 Joule for ascast condition, neem oil, water and SAE 40 engine oil respectively. The decreased in the impart energy value as the hardness increases are in agreement with the earlier research of Muhammad [12] after quenching steel and ductile cast iron in various media. Neem oil developed impact strength between that of SAE engine 40 oil and water.

It is noteworthy to know that higher hardness was obtained for the neem oil than the SAE engine oil (see Figures 1-2). The hardness values of the water quenched and the observed microstructure conform to the expectation. The degree of the free fatty acid value in the neem oil and the iodine value (see Table 2) which shows the amount of reactive radicals present and the stability of the fatty acid molecule film that form on the metal surface [7] may be responsible for the result obtained for neem oil in this research.

\section{CONCLUSIONS}

The effectiveness of the neem oil as quenching medium in the hardening process of plain carbon steel and ductile cast iron has been quantitatively assessed using hardness values and impact energy in particular. From the results obtained in this study, the following conclusions can be drawn;

1. Neem oil have a hardness value less than that of water but higher hardness value than that of SAE40 engine oil. Hence, Neem oil can be used where cooling severity less than water but greater than SAE 40 engine oil is required for hardening of plain carbon steel and ductile cast iron.

2. Neem oil can be used to improve the toughness of these samples since it has higher impact energy values than water which is the common quenching medium. 
3. The hitherto neem oil can be utilized as quenching medium, as a replacement for water and SAE 40 engine oil in hardening process for plain carbon steels and ductile cast iron.

\section{REFERENCES}

[1] Morrogh, H. (1948): Anew Engineering Materials Production of Nodular Graphite Structures in grey cast irons. AASM pp. 72-90.

[2] Larry Olson (2001): Proper Quenching Option yields Heat Treating Results. pp 1-5.

[3] Rajan T. V. and C. P. Sharma (1988): Heat Treatment, Principles and Techniques. PrenticeHall of New Delhi-India. pp. 143-150, 236-380.

[4] Gulyaev A. (1980): Physical Metallurgy. Vol 1, Mir Pubilshers Moscow. pp 154-198.

[5] Higgins R.A. (1995): Engineering Metallurgy. Edward Arnold UK, pp 218-257, 285-354.

[6] Hassan, S. B, Balogun, S.O and Aigbodion, V. S(2009): Hardening Characteristics of Medium Carbon Steel Using Fresh Cassava Liquid Extract as Quenchants Journal o Metallurgy and Materials Engineering, 4, No2, 55-61.

[7] Hassan, S. B(2003): Hardening Characteristics of Plain Carbon Steel Using Fatty- based oils as Quenchants, NSE, Technical Transactions, 38, 19-29.

[8] Srikanth.V(2003): Establishment of Katsina Neem Factory, National ResearchInstitute for chemical Technology, Zaria Nigeria. 1-4.

[9] Williams .E.J(2009):Evaluation of Neem oil as a Quenching medium for medium Carbon Steel and Ductile cast iron (Unpublished B-ENG project), Department of Metallurgical Engineering, Ahmadu Bello University, Zaria, Nigeria.

[10] American Society of Metals (ASM); Metal Hand book.: Material Park OH, 1995, pp. 822 873

[11] Totten, G. E(1990): 'Polymer Quenchants: The basics'. Advance Material Production, Vol 137, No.3, pp.51-53.

[12] Muhammed, T.I(2007): Evaluation of polymer glycerol for hardening process in steel and cast iron, MSc Seminar, Department of Metallurgical Engineering, Ahmadu Bello University, Zaria, P. 34 